\title{
EWSR1/ATF1 Fusion Protein Type 2
}

National Cancer Institute

\section{Source}

National Cancer Institute. EWSR1/ATF1 Fusion Protein Type 2. NCI Thesaurus. Code C99223.

A fusion protein (432 aa, $46 \mathrm{kDa}$ ) encoded by the EWSR1/ATF1 fusion gene. This protein is comprised of the transactivation domain of the RNA-binding protein EWS followed by the DNA-binding basic domain and leucine zipper dimerization domain of the cyclic AMP-dependent transcription factor AT F-1 protein. 